\title{
Erratum to: Gender differences in contrast-enhanced magnetic resonance imaging after acute myocardial infarction
}

\author{
Birgit Langhans · Tareq Ibrahim • Jörg Hausleiter • \\ Carolin Sonne · Stefan Martinoff • Albert Schömig • \\ Martin Hadamitzky
}

Published online: 7 April 2013

(C) Springer Science+Business Media Dordrecht 2013

\section{Erratum to: Int J Cardiovasc Imaging \\ DOI 10.1007/s10554-012-0132-3}

The original publication of the article contains error in the Abstract section. The sentence starting with "We prospectively analyzed ..." should read as "We prospectively analyzed patients $(\mathrm{n}=448)$ with AMI and primary angioplasty, who underwent contrast-enhanced cardiac magnetic resonance (CMR) imaging on a $1.5 \mathrm{~T}$ scanner in median 5 $[4,6]$ days after the acute event. CMR scar size was measured 15 min after gadolinium injection."

The online version of the original article can be found under doi:10.1007/s10554-012-0132-3.

B. Langhans

Institute for Clinical Radiology, Ludwig-Maximilians-University

Hospital Munich, Ziemssenstraße 1, 80336 Munich, Germany

e-mail: birgit.langhans@med.uni-muenchen.de

T. Ibrahim · J. Hausleiter · C. Sonne · A. Schömig

Klinik für Herz- und Kreislauferkrankungen, Deutsches

Herzzentrum München, Lazarettstraße 36, 80636 Munich,

Germany

S. Martinoff · M. Hadamitzky ( $\square)$

Institut für Radiologie und Nuklearmedizin, Deutsches

Herzzentrum München, Lazarettstraße 36, 80636 Munich,

Germany

e-mail: mhy@dhm.mhn.de 